RESEARCH ARTICLE

Sokoto Journal of Veterinary Sciences

(P-ISSN 1595-093X: E-ISSN 2315-6201)

http://dx.doi.org/10.4314/sokjvs.v17i3.2

Bappah et al./Sokoto Journal of Veterinary Sciences, 17(3): 9 - 16.

\title{
Correlation of ultrasonographic renal volume with modified body mass index in Nigerian indigenous dogs
}

\author{
MN Bappah ${ }^{1 *}$, CA Awasum ${ }^{1}$, ND Chom ${ }^{2}$, M Lawal $^{1}$, UM Bello ${ }^{3}$, AA Bada ${ }^{1}$, SY \\ Idris $^{4}$ \& GE Ochube ${ }^{1}$ \\ 1. Department of Veterinary Surgery and Radiology, Ahmadu Bello University, Zaria, \\ Nigeria \\ 2. Department of Radiology, Ahmadu Bello University Teaching Hospital, Zaria, Nigeria \\ 3. Laboratory of Cell Biology and Histology, Department of Veterinary Anatomy, Ahmadu \\ Bello University, Zaria, Nigeria \\ 4. Department of Veterinary Pathology, Ahmadu Bello University, Zaria, Nigeria
}

\begin{abstract}
Copyright: (C) 2019
Bappah et al. This is an open-access article published under the terms of the Creative Commons Attribution License which permits unrestricted use, distribution and reproduction in any medium, provided the original author and source are credited.
\end{abstract}

*Correspondence: Tel.: +2348184337799; E-mail: mnbappah.88@yahoo.com
The aim of this study was to determine the relationship between ultrasonographic kidney volume and modified body mass index through evaluating the kidney architectural appearance, variations between right and left kidney dimensions and correlation between ultrasonographic kidney volumes and modified body mass index in clinically healthy Nigerian indigenous dogs. The ultrasonography was performed to obtain the kidney dimensions in centimeter for the length (bipolar length), width and height of the kidney for both right and left kidneys to compute for the kidney volume in centimeter cube using the formula for the volume of an ellipsoid ( $\mathrm{L}$ X W X H X 0.523), while the modified body mass index for dogs was obtained by taking the body weight in kilogram of each dog against the squared length of the trunk. The serum creatinine and urea parameters are within normal limits in dogs used for this study. This research revealed normal kidney architecture with hyperechoic renal capsules, hypoechoic renal cortex, anechoic medullary pyramids and hyperechoic renal pelvis. Left kidneys are significantly larger than the right kidneys and there was a weak positive correlation between right $\left(r^{2}=0.21\right)$ and left $\left(r^{2}=0.18\right)$ kidney volumes with modified body mass index in clinically healthy in Nigerian indigenous dogs. In conclusion, the left kidney appeared larger than the right kidney and there is a positive but weak relationship between ultrasonographic kidney volume and modified body mass index in healthy Nigerian indigenous dogs.

\section{Introduction}

Canine kidney diseases pose diagnostic challenges due to their varying clinical presentations. Kidneys are located in the retroperitoneal region (Burk \& Feneey, 2003) that performs vital functions in the body such as excreting waste products, maintaining homeostasis, blood production and utilization of mineral calcium (Fitzgerald et al., 2011). Many kidney diseases are associated with changes in kidney dimensions (Sohn et al., 2016), therefore, the knowledge of normal kidney volume is important, as it can be used for the morphological diagnosis of kidney diseases (Barrera et al., 2009) and also useful in monitoring of transplanted kidney (Nyland et al., 1997). A method introduced by Mareschal et al. (2007) which is the ratio of the kidney length to the aortic luminal diameter as a means to access the kidney size, it has a drawback in the measurement of aortic luminal diameter 
which is greatly affected by diastolic and systolic phases of cardiac cycle. While kidney volume has since been considered as an accurate and reproducible linear ultrasonographic kidney measurement used in kidney diagnosis in dogs (Nyland et al., 1989; Barr, 1990; Felkai et al., 1992). Some researchers are of the opinion that normal measurement for canine kidney volume should be based on individual breed because of body size disparity among numerous breed of dogs (Lobacz et al., 2012) and researches have reported a positive relationship between the ultrasonographic kidney volume and body weight in dogs (Nyland et al., 1989; Barr, 1990; Felkai et al., 1992; Sampaio \& Araujo, 2002), but there were no available information on its relationship with modified body mass index in dogs.

Body mass index is a predominant indicator for the amount of body fat (Pasco et al., 2014). Body mass index has been considered as health indicator because overweight and obesity are implicated as consequence of metabolic syndrome (MurguiaRomero et al., 2012). In dogs, there is a strong linkage between overweight and obesity with kidney conditions such as chronic kidney disease (Parker and Freeman, 2011; Tvarijonaviciute et al., 2013), urolithiasis (Lekcharoensuk et al., 2000) and cancer (Glickman et al., 1989; German, 2006) as well as kidney cancer in human (Bhaskaran et al., 2014). However, some researchers suggested a modified body mass index for dogs due to the facts of being in pronograde posture, which has great difference in body shapes from that of human (Thengchaisri et al., 2014). Body mass index is an objective means of accessing the body condition system through size and weight (Adetola et al., 2016), unlike body condition score which is a subjective evaluation of the body condition system (Laflamme, 1997) that does not consider different body sizes of dogs.

Nigerian indigenous dogs are a medium size breed of dogs with moderate hair length and mesocephalic cranial index. There is a paucity of information on the relationship between ultrasonographic kidney volume with modified body mass index parameters in Nigerian indigenous dogs which its clinical importance can be related to the morphological diagnosis of kidney diseases (Nyland et al., 1989; Barr, 1990; Sampaio \& Araujo, 2002; Barrera et al., 2009), therefore there is the need to unveil the relationship between the ultrasonographic kidney volume and modified body mass index in Nigerian indigenous dogs. The aim of this study was to determine the relationship between ultrasonographic kidney volume and modified body mass index through evaluating the kidney architectural appearance, variations between right and left kidney dimensions and correlation between ultrasonographic kidney volumes and modified body mass index in clinically healthy Nigerian indigenous dogs.

\section{Materials and Methods}

Animal subjects

One hundred and fifteen (115), males (77) and females (38) apparently healthy Nigerian indigenous dogs in Zaria, with ages ranged from 1 to 4.5 years were selected. The research was performed only on dogs considered healthy on the basis of physical examination, body condition score of 3 using 5 points scale (Baldwin et al., 2010), normal serum biochemical profile (Creatinine and Urea). While dogs with the history of renal disease, sonographic anomalies of kidneys, neutered and pregnant dogs were excluded from the research. All experimental procedures and protocol were reviewed and approved by the Ethical Committee of the Ahmadu Bello University, Animal Care and Use Committee (ABUCAUC/2017/008) and informed consent was obtained from all the dog owners, prior to the commencement of the study.

Typical features of Nigerian indigenous dog used in this research that serves as the breed identification were average body size, moderate hair length and mesocephalic cranial index (Plate I).

\section{Kidney ultrasonography}

The conscious dogs were humanely restrained physically on dorsal recumbency then the ventrum was clipped from the xiphoid process that runs lateral ways along the caudal border of the last rib and extends posteriorly to the umbilical scar to adequately provide scanning space. After clipping of hairs, aquostic gel (Nacal Medical, England) was liberally applied to both the probe's scanning surface and the clipped area on the ventrum. Scanning procedure was carried out using portable digital B-mode scan machine (C5 ${ }^{\mathrm{TM}}$ Sonostar Technologies Co., Guangzhou, Guangdong, China) using a $5.0 \mathrm{MHz}$, curvilinear electronic transducer suitable for veterinary use. Sagittal and transverse planes scan of right and left kidneys were carried out. The left kidney was located between $L_{1}-L_{3}$ with its cranial pole having contact with greater curvature of the stomach and the spleen on its dorsomedial aspect, while the caudal pole having contact with small intestines and the descending colon. The right kidney was deeper and cranially located in the para-costal region located between $\mathrm{T}_{12}-\mathrm{L}_{1}$ with its cranial pole having contact with caudate lobe of the liver and right pancreatic lobe ventromedially. To and fro movement of the transducer at these locations aided focusing of the ultrasound impulse on the kidneys in order to be visible on the B-mode monitor. Once there was a 
clear image of the kidney on the monitor, the freeze button on the keyboard of the ultrasound machine was pressed and distance measurement mode was activated. To obtain the kidney dimensions in centimeter for both right and left kidneys, scanning on sagittal plane was used to obtained the cranial to caudal poles for measurement of the length of the kidney (bipolar length) (Plate II), while on transverse plane, width (Plate III) and height (Plate IV) of the kidney was recorded by measuring from the medial limit to the lateral limit along the hilus of the kidney and measuring the distance from the dorsal limit to the ventral limit of the kidney respectively. The kidney volume in centimeter cube was estimated using the formula for the volume of an ellipsoid which is the product of kidney length, width, height and 0.523 ( $\mathrm{V}=\mathrm{L}$ X W X H X 0.523) (Barrera et al., 2009).

\section{Modified body mass index measurement}

The dogs were restrained physically on standing position. Modified body mass index was evaluated by taking the body weight with the aid of a sensitive digital weighing scale (Kubei ${ }^{\mathrm{TM}}$ ) in kilogram for each dog as against the length of the trunk (truncal length) obtained by tape measurements in meters then squared $\left(\mathrm{m}^{2}\right)$ from the crest of humeral greater tubercle to the level of ischiatic tubercle at the hind limbs (Thengchaisri et al., 2014). The truncal length rather than height was used for the modified body mass index calculation, due to dog's pronograde posture, which has a great difference in body shapes scompared to that of humans.

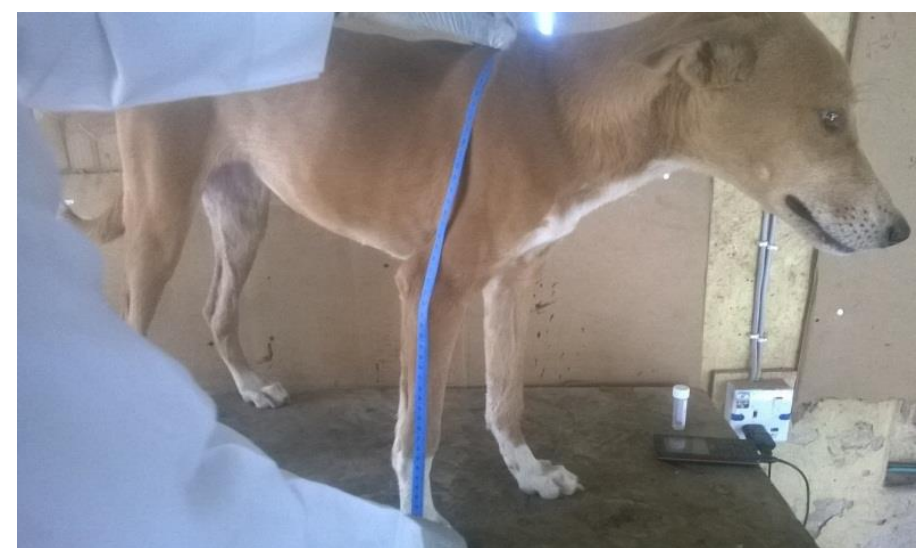

Plate I: A typical features of Nigerian indigenous dog with average body size, moderate hair length and mesocephalic cranial index

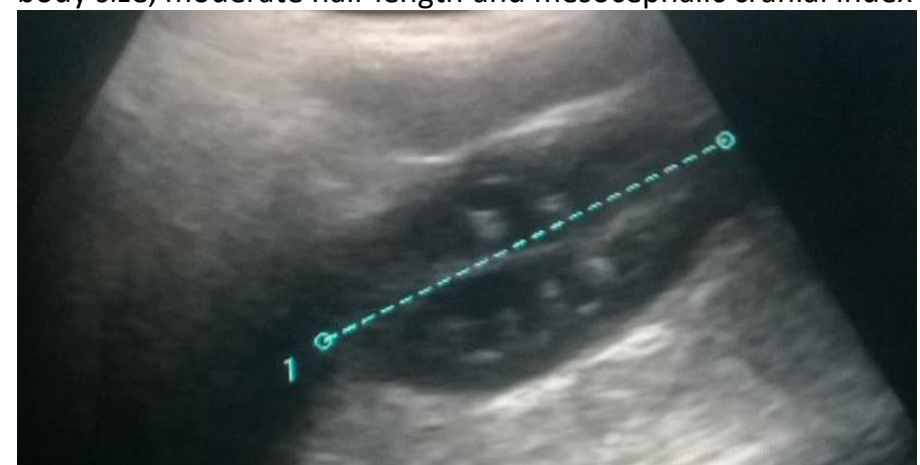

Plate II: Sonographic measurement of kidney length on sagittal plane

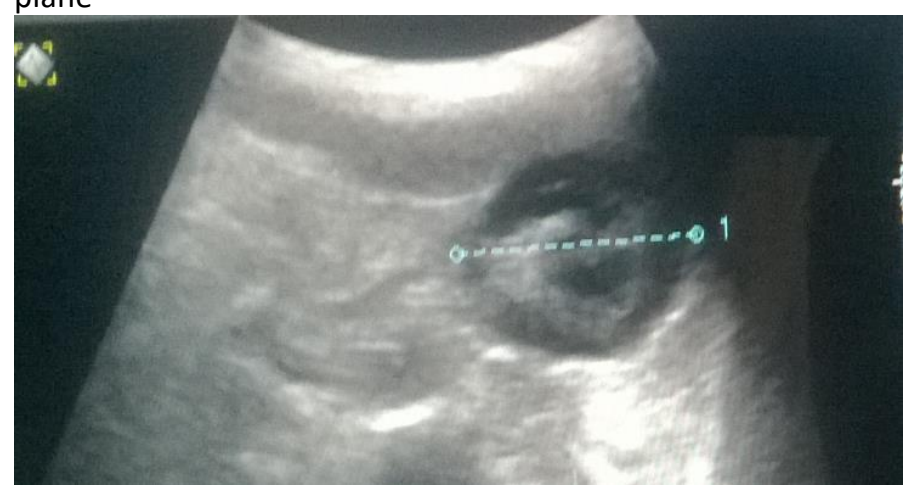

Plate III: Sonographic measurement of kidney width on transverse plane
MBMI $\left(\mathrm{kg} / \mathrm{m}^{2}\right)=$ weight of animal $(\mathrm{kg})$ Truncal length of animal $\left(\mathrm{m}^{2}\right)$

\section{Statistical analysis}

Data collected were subjected to statistical analysis using Graph Pad Prism ${ }^{\circledast}$ version 5.0 and mean \pm SD for each subject was calculated. A paired Ttest was conducted to compare data obtained between right and left kidneys and Pearson's correlation coefficient test was used to relate kidney dimensions with modified body mass index. The values of $P \leq 0.05$ were considered significant.

\section{Results}

Evaluation of biochemical parameters Mean \pm SD of the serum creatinine and urea in Nigerian indigenous dogs are $74.13 \pm 24.86$ and $4.31 \pm 1.23$ respectively (Table 1 ).

\section{Appearance of normal kidneys}

On sagittal plane, the shape of the kidneys appeared elongated which are outlined by renal capsules which were represented by a very thin hyperechoic line, immediately after the renal capsule, cortex which is shown to be hypoechoic with smooth echotexture, then medullary pyramids which represent pocket anechoic regions that are surrounded by irregular hyperechoic septa and the centrally located hyperechoic renal pelvis. While on transverse plane, it appeared oval with peripheral hypoechoic and central hyperechoic. 


\section{Paired kidney evaluations}

Mean \pm SD values of the measurement of the right and left kidney volumes are $26.33 \pm 10.10 \mathrm{~cm}^{3}$ and $32.36 \pm 11.10 \mathrm{~cm}^{3}$ respectively for Nigerian indigenous dogs, while the ranges and mean \pm SD of the measurement of length, width and height of the right and left kidneys of Nigerian indigenous dogs (Table 2). The left kidney dimensions appeared larger than the right kidney and values for the variation in dimension between the paired kidneys in Nigerian indigenous dogs revealed significant

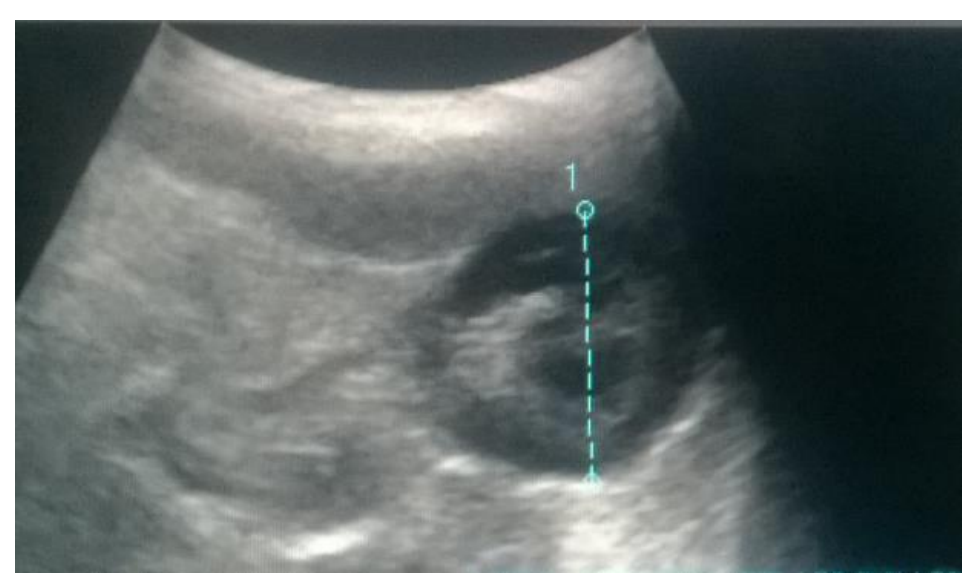

Plate IV: Sonographic measurement of kidney height on transverse plane differences $(P<0.05)$ as in kidney length $(0.0028)$, kidney width (0.0065), kidney height (0.0001) and kidney volume (0.0001) (Table 2$)$, so this deduced that left kidneys is statistically larger than the right kidneys in Nigerian indigenous dogs.

Relationship between ultrasonographic kidney volumes with modified body mass index

Ranges and mean \pm SD values of the measurement of the ultrasonographic kidney dimensions for Nigerian indigenous dogs (Table 2) and the Nigerian indigenous dogs ranges from $35.60 \mathrm{Kg} / \mathrm{m}^{2}$ to $98.14 \mathrm{Kg} / \mathrm{m}^{2}$ with mean \pm SD of $56.56 \pm 11.50$ $\mathrm{Kg} / \mathrm{m}^{2}$. Correlation between ultrasonographic kidney volumes with modified body mass index in Nigerian indigenous dogs using Pearson's coefficient, showed a weak positive relationship in both right and left kidney volumes as 0.21 and 0.18 respectively (Table 3 ), which are graphically represented in Figure 1 and 2 respectively.

Table 1: Evaluation of Biochemical parameters of Nigerian indigenous dogs used in the study

\begin{tabular}{llll}
\hline Biochemical parameters & Mean \pm SD & Range & Reference values $^{*}$ \\
\hline Creatinine (umol/l) & $74.13 \pm 24.86$ & $45.25-125.50$ & $40.00-130.00$ \\
Urea (mmol/l) & $4.31 \pm 1.23$ & $2.80-6.10$ & $2.50-7.00$ \\
\hline
\end{tabular}

Reference values* (Bush, 1993)

Table 2: Mean right and left kidney dimensions and their comparison in clinically healthy Nigerian indigenous dogs $\mathrm{n}=$ 115

\begin{tabular}{llllll}
\hline & \multicolumn{4}{c}{ Kidney dimensions } & \\
\cline { 2 - 5 } Variables & \multicolumn{3}{c}{ Right kidney } & \multicolumn{2}{c}{ Left kidney } \\
Range & Mean \pm SD & Range & Mean \pm SD & Variation (P values) \\
\hline Kidney length $(\mathrm{cm})$ & $3.86-7.40$ & $5.54 \pm 0.71$ & $4.12-7.57$ & $5.81 \pm 0.66$ & $0.0028^{* *}$ \\
Kidney width $(\mathrm{cm})$ & $1.86-5.00$ & $3.15 \pm 0.60$ & $2.04-5.42$ & $3.36 \pm 0.53$ & $0.0065^{* *}$ \\
Kidney height $(\mathrm{cm})$ & $1.77-4.40$ & $2.79 \pm 0.49$ & $1.84-4.64$ & $3.10 \pm 0.56$ & $0.0001^{* * *}$ \\
Kidney volume $\left(\mathrm{cm}^{3}\right)$ & $9.22-63.20$ & $26.33 \pm 10.10$ & $13.66-70.21$ & $32.36 \pm 11.10$ & $0.0001^{* * *}$ \\
\hline
\end{tabular}

Table 3: Correlation of kidney dimensions with modified body mass index in Nigerian indigenous dogs

\begin{tabular}{|c|c|c|}
\hline Parameters & $\begin{array}{l}\text { Right kidney } \\
\text { Correlation }\end{array}$ & $\begin{array}{l}\text { Left kidney } \\
\text { Correlation }\end{array}$ \\
\hline Kidney length (cm) & $0.30^{\times x}$ & $0.37^{\times \times \times}$ \\
\hline Kidney width $(\mathrm{cm})$ & 0.083 & -0.057 \\
\hline Kidney depth (cm) & $0.22^{x x}$ & $0.18^{x}$ \\
\hline Kidney volume $\left(\mathrm{cm}^{3}\right)$ & $0.21^{x}$ & 0.18 \\
\hline$* \quad \mathrm{P} \leq 0.05$ & & \\
\hline$P \leq 0.01$ & & \\
\hline$P \leq 0.001$ & & \\
\hline
\end{tabular}




\section{Discussion}

The kidney is an intra-abdominal organ usually located in the retroperitoneal space (Burk \& Feeney, 2003). Its ultrasonographical image revealed renal cortex with mild echogenicity with finely granular particles, while renal medulla and pelvis are anechoic and irregular hyperechoic appearance respectively and these findings were coincided with the findings done by other researchers (Moarabi et al., 2011; Barman \& Gaikwad, 2014). The ultrasonographic images of the kidney were obtained using a curvilinear transducer with a frequency of 5.0 $\mathrm{MHz}$, unlike linear transducers that are also suitable for kidney of infants, the convex surface of the curvilinear transducer enabled wide area of impulse coverage and deep tissues penetration and also appropriate for adult subjects like in the case of this study (Saul et al., 2011; Dimitrov, 2012; Wieczorek et al., 2013; Hansen et al., 2016).

The left kidney is significantly large in both male and female Nigerian indigenous dogs. Some studies in Dachshund (Cunha et al., 2009) and German shepherd (Kolber \& Borelli, 2005) dogs support this finding, while a study reported that right kidney is larger than the left kidney (Mareschal et al., 2007) and others reported no differences between right and left

kidneys (Sampaio \& Araujo,2002; Barella et al., 2012; Jeyaraja et al., 2015). The variations in this study were due to disparity in body size among various breeds of dogs as explained by Lobacz et al. (2012). In human, studies reported the left kidney being larger than the right kidney (Hollinshead, 1971; Raza et al., 2011), in explanation for this was suggested by Karim et al. (2015) that variation which could be because hepatic tissue may hinder longitudinal development of the right kidney whereas left kidney has liberty for maximum growth without hindrance. Another possible suggestion in human, which could be that the left renal artery being shorter than the right, therefore allow increased blood flow that may cause a slight increase in left kidney volume (Okur et al., 2014). Though, puppies above 6 months of age were not evaluated, due to absence of linear transducer and this forms a limitation in the study design, because England (1996) stated that kidneys of puppies at 6 months of age measures proportionately with their body size.

Modified body mass index for dogs is considered in this study because dogs are quadrupeds, so it is preferred to use the truncal length (length of the trunk) of the animal instead of the height as in human, which leads to the establishment of an appropriate morphometric dimension for dogs known as modified body mass index for dogs, as the weight in kilograms per truncal length in meter square (Thengchaisri et al., 2014). Even though, some researchers have attempted using the human body mass index for dogs (Koc et al., 2009; Adetola et al., 2016) but its value increases as the height decrease thereby becoming an inappropriate index for medium and smaller breed of dogs (Adetola et al., 2016). There were weak positive correlations between ultrasonographic kidney volume and modified body mass index in Nigerian indigenous dogs. Unfortunately, the correlation between ultrasonographic kidney volume and modified body 
mass index have not yet been reported in the literature for healthy dogs and to the best of our knowledge, the results obtained in this study is the first to be reported in this species. Several studies in dogs also reported a positive correlation between kidney dimensions and body weight (Nyland et al., 1989; Barr, 1990; Felkai et al., 1992; Sampaio \& Araujo, 2002). However, in human, there were also studies that reported a positive correlation between kidney dimensions and body mass index (Safak et al., 2005; Shin et al., 2009), while, some studies opposed the findings (Emamian et al., 1993; Egberongbe et al., 2010). Correlation between the kidney and morphometric dimensions have recently become accepted in the diagnosis of nephropathies (Sampaio \& Araujo, 2002; Okur et al., 2014). Another limitation to this study was that, dogs with various body condition score were not considered in order to compare its relationships with their ultrasonographical kidney dimensions.

Conclusively, the left kidney appeared larger in dimensions than the right kidney in Nigerian indigenous dogs and correlation between modified body mass index for dogs and ultrasonigraphic kidney volume reveals positive linear relationship with significant correlation with right kidney volume in Nigerian indigenous dogs.

\section{Acknowledgements}

The success of the research would be accredited to Ahmadu Bello University Veterinary Teaching Hospital, Zaria, for their support in assisting with ultrasound equipment.

\section{Conflicts of Interest}

The authors declare no conflicts of interest.

\section{References}

Adetola AR, Oluwatobiloba AR \& Abosede AA (2016). Evaluation of body mass index and plasma lipid profile in boerboel dogs. Nigerian Journal of Physiological Sciences, 31(1): 77-81.

Barella G, Lodi M, Sabbadin LA \& Faverzani S (2012). A new method for ultrasonographic measurement of kidney size in healthy dogs. Journal of Ultrasound, 15(3): 186191.

Baldwin K, Bartges J, Buffington T, Freeman LM, Grabow M, Legred J \& Ostwald D (2010). AAHA Nutritional assessement guidelines for dogs and cats. Journal of the American Animal Hospital Association, 46(4): 285296.

Barman D \& Gaikwad RV (2014). Evaluation of kidney status by ultrasonography in canines: an experimental study. Research in Agriculture Livestock and Fisheries, 1(1): 105-108.

Barr FJ (1990). Evaluation of ultrasound as a method of assessment renal size in the dog. Journal of Small Animal Practice, 31(4): 174-179.

Barrera R, Duque J, Ruiz P \& Zaragoza C (2009). Accuracy of ultrasonographic measurements of kidney dog for clinical use. Revista Cientifica, 19(6): 576-583.

Bhaskaran K, Douglas I, Forbes H, Dos-Santos-Silva I, Leon DA \& Smeeth L (2014). Body-mass index and risk of 22 specific cancers: a population-based cohort study of $5 \cdot 24$ million UK adults. Lancet, 384(9945): 755765.

Burk RL \& Feeney DA (2003). Abdomen: Kidney. In: Small Animal Radiology and Ultrasonography (R Kersey, D LeMelledo, editors). Saunder, USA. Pp 262-263.

Bush BM (1993). Renal Disorders. In: Interpretation of Laboratory Results for Small Animal Clinicians. Blackwell scientific Publisher, Oxford. Pp 299-310.

Cunha LMF, Gallo JMS \& Canabrava HAN (2009). Renal volume by ultrasonographic linear measures in Dachshund dogs. In: Proceedings of the thirty-fourth World Small Animal Veterinary Association World Congress, Sao Paulo, Brazil. http://www.vin.com/apputil/content/def aultadv1. aspx?pld=11290\&id=4253061, retrieved 16-10-2017.

Dimitrov RS (2012). Ultrasound features of kidneys in the rabbit (Oryctolagus cuniculus). Veterinary World, 5(5): 274-278.

Egberongbe AA, Adetiloye VA, Adeyinka AO, Afolabi OT, Akintomide AO \& Ayoola OO (2010). Evaluation of renal volume by ultrasonography in patients with essential hypertension in Ile-Ife, south western Nigeria. Libyan Journal of Medicine, 5(1): 4848.

Emamian SA, Nielson MB \& Pedersen JF (1993). Kidney dimensions at sonography: correlation with age, sex and habitus in 665 adult volunteers. American Journal of Roentgenology, 160(1): 83-86.

England GCW (1996). Renal and hepatic ultrasonography in the neonatal dog. Veterinary Radiology and Ultrasound, 37(5): 374-382.

Felkai C, Voros K, Vrabely T, Vetesi F \& Karsai F (1992). Ultrasonographic determination of renal volume in the dog. Veterinary Radiology and Ultrasound, 33(5): 292-296.

Fitzgerald SD, Bartges JW, Brown SA, Sanderson SL \& Wallace MS (2011). The Urinary system 
of dogs. Merck Manual Pet Health Edition. http://www.merckvetmanual.com/pethea Ith/dog_disorders_and_diseases/kidney_a nd_urinary_tract_disorders_of_dogs/the urinary_system_of_dogs.html, retrieved 28-08-2016.

German AJ (2006). The growing problem of obesity in dogs and cats. Journal of Nutrition, 136(7): 1940S-1946S.

Glickman LT, Schofer FS, McKee LJ, Reif JS \& Goldschmidt $\mathrm{MH}$ (1989). Epidemiologic study of insecticide exposure, obesity, risk of bladder cancer in household dogs.Journal of Toxicology and Environmental Health, 28(4): 407-414.

Hansen KL, Nielsen MB \& Ewertsen C (2016). Ultrasonography of the kidney: a pictorial review. Diagnostics, 6(1): 2.

Hollinshead WH (1971). The Kidneys, Ureters and Suprarenal Gland. In: Anatomy for Surgeons: The Thorax, Abdomen and Pelvis, (2nd edition). Harper and Row Publisher, New York. Pp 518.

Jeyaraja K, Hamsa-Yamini S \& Thirunavukkarasu PS (2015). Sonographic evaluation of kidneys in dogs with acute and chronic kidney disease. International Journal of Advanced Research, 3(9): 555 - 564.

Karim SH, Mohammed NA, Ahgaways IHA \& Mohammed BA (2015). Comparative ultrasonographic measurement of renal size and its correlation with age, gender and body mass index in Normal subjects in Sulaimani Region. European Scientific Journal, 11(12): 236-250.

Koc D, Dogan A \& Bek B (2011). Effect of gender, facial dimensions, body mass index and type of functional occlusion on bite force. Journal of Applied Oral Science, 19(3): 274279.

Kolber M \& Borelli V (2005). The kidney's measurement in German Shepherd using the ultrasonography method. Revista do Instituto de Ciencias da Saude, 23(1): 1924.

Laflamme DP (1997). Development and validation of a body condition score system for cats: a clinical tool. Feline practice, 25(5): 13-17.

Lekcharoensuk C, Lulich JP, Osborne CA, Pusoonothornthum R, Allen TA, Koehler LA, Urlich LK, Carpenter KA \& Swanson LL (2000). Patient and environmental factors associated with calcium oxalate urolithiasis in dogs. Journal of American Veterinary Medical Association, 217(4): 515-519.
Lobacz MA, Sullivan M, Mellor D, Hammond G, Labruyere J \& Dennis R (2012). Effect of breed, age, weight and gender on radiographic renal size in the dog. Veterinary Radiology and Ultrasound, 53(4): 437-41.

Mareschal A, D'anjou MA, Moreau M, Alexander K \& Beauregard G (2007). Ultrasonographic measurement of kidney-to-aorta ratio as a method of estimating renal size in dogs. Veterinary Radiology and Ultrasound, 48(5): 434-438.

Moarabi A, Mosallanejad B, Ghadiri RA \& Borujeni MP (2011) Ultrasonographic evaluation of the urinary system in New Zealand white rabbit and Tolai hare. Veterinary Research Forum, 2(2): $113-120$.

Murguia-Romero $M$, Jimenez-Flores $R$, VillalobosMolina R, Mendoza-Ramos MI, Reyes-Reali J, Sigrist-Flores SC \& Mendez-Cruz AR (2012). The body mass index (BMI) as a public health tool to predict metabolic syndrome. Journal of Preventive Medicine, 2(1): 59-66.

Nyland TG, Kantrowitz BM, Fisher P, Olander HJ \& Hornof WJ (1989). Ultrasonic determination of kidney volume in the dog. Veterinary Radiology, 30(4): 174-180.

Nyland TG, Fisher PE, Gregory CR \& Wisner ER (1997). Ultrasonographic evaluation of renal size in dogs with acute allograft rejection. Veterinary Radiology and Ultrasound, 38(1): 55-61.

Okur A, Serin HI, Zengin K, Erkoc MF, Tanik S, Yildirim U, Karaçavus S \& Akyol L (2014). Relationship between kidney volume and body indexes in the Turkish population determined using ultrasonography. International Brazilian Journal of Urology, 40(6): 816-822.

Parker VJ \& Freeman LM (2011). Association between body condition and survival in dogs with acquired chronic kidney disease. Journal of Veterinary Internal Medicine, 25(6): 1306-1311.

Pasco JA, Holloway KL, Dobbins AG, Kotowicz MA, Williams L \& Brenan S (2014). Body mass index and measures of body fat for defining obesity and underweight: a crosssectional, population-based study. BMC Obesity 1(1): 9.

Raza M, Hameed A \& Khan MI (2011). Ultrasonographic assessment of renal size and its correlation with body mass index 
in adults without known renal disease. Journal of Ayub Medical College Abbottabad, 23(3): 64-68.

Safak AA, Simsek E \& Bahcebasi T (2005). Sonographic assessment of the normal limits and percentile curves of liver, spleen and kidney dimensions in healthy schoolaged children. Journal of Ultrasound in Medicine, 24(10): 1359-1364.

Sampaio KMOR \& Araujo RB (2002). Ultrasonographic measurement of linear characteristics and renal volumetry in dogs. Brazilian Journal of Veterinary and Animal Science, 54(3): 50-54.

Saul T, Rivera MDR \& Lewiss R (2011). Focus On: Ultrasound Image Quality. American College of Emergency Physicians. https://www.acep.org/Content.aspx?id=7 9787\#sm.0008ukc0m15ehd9hwg626p6xe 2zlq, retrieved 10-01-2018.

Shin HS, Chung BH, Lee SE, Kim WJ, Ha HI \& Yang CW (2009). Measurement of kidney volume with multi-detector computed tomography scanning in young Korean. Yonsei Medical Journal, 50(2): 262-265.

Sohn J, Yun S, Lee J, Chang D, Choi M \& Yoon J (2016). Reestablishment of radiographic renal size in Miniature Schnauzer dogs. Journal of Veterinary Medical Science, 78(12): 1805-1810.

Thengchaisri Thengchaisri N, Theerapun W, Kaewmokul S \& Sastravaha A (2014). Abdominal obesity is associated with heart disease in dogs. BMC Veterinary Research, 10(1): 131.

Tvarijonaviciute A, Ceron JJ, Holden SL, Biourge V, Morris PJ \& German AJ (2013). Effect of weight loss in obese dogs on indicators of renal function or disease. Journal of Veterinary Internal Medicine 27(1): 31-38.

Wieczorek AP, Wozniak MM \& Tyloch JF (2013). Errors in the ultrasound diagnosis of the kidneys, ureters and urinary bladder. Journal of Ultrasonography 13(54): 308318. 